\title{
LOS AROS DE PLATA DE PATAGONIA SEPTENTRIONAL: APORTES DE LA COLECCIÓN HENRY DE LA VAULX (1896) SOBRE FORMA, TECNOLOGÍA Y METALURGIA
}

\author{
THE SILVER EARRINGS OF NORTHERN PATAGONIA: \\ THE CONTRIBUTION OF THE HENRY DE LA VAULX COLLECTION (1896) \\ TO FORM, TECHNOLOGY AND METALLURGY
}

\author{
Paz Núñez-Regueiro ${ }^{1}$ y María Filomena Guerra²
}

\begin{abstract}
Los estudios sobre joyería indígena de Patagonia han privilegiado las colecciones procedentes de Araucanía (centro-sur de Chile), considerando en menor escala la producción platera de la vertiente oriental de los Andes en el siglo diecinueve. Este artículo presenta los resultados obtenidos del estudio de los aros de plata reunidos en 1896 por Henry de La Vaulx en la toldería del cacique Valentín Saygüeque (1830-1903), famoso por el tesoro monetario y platero acumulado antes de su derrota militar en 1882, cuando encabezaba un grupo de orígenes mixtos huilliche, pehuenche, pampa y tehuelche que controlaba el "País de las Manzanas" (provincia de Neuquén, Argentina). El análisis formal, tecnológico y físico-químico de la colección conservada en el Musée du quai Branly de Paris ofrece una primera síntesis sobre una producción platera contextualizada geográfica y cronológicamente, así como criterios analíticos para la datación de la joyería indígena.
\end{abstract}

Palabras claves: metalurgia, platería, aros, plata, mapuche, tehuelche, Patagonia, La Vaulx.

Previous studies conducted on indigenous jewellery from Patagonia have focused on collections from Araucania (Centre-South of Chile), and to a smaller degree on the 19th-century silver production from the Eastern Andean cordillera. This work presents the results obtained from the study of the silver earrings collected by Henry de La Vaulx in Valentín Saygüeque's camp (1830-1903). Saygüeque was a cacique (chief) renowned for the monetary and jewellery treasure he had accumulated prior to his military defeat of 1882, period during which he led a group of mixed huilliche, pehuenche, pampa and tehuelche origins who controlled the "País de las Manzanas" (the Land of Apples) (province of Neuquén, Argentina). The formal, technological and chemical analysis of the collection kept at the Musée du quai Branly in Paris offers a first summary of a geographically and chronologically contextualized silver production, and provides analytical criteria for the dating of native jewellery.

Key words: Metallurgy, silverwork, earrings, silver, mapuche, tehuelche, Patagonia, La Vaulx.

Partiendo de una producción limitada que tiene sus raíces en los tiempos prehispánicos y colonial (Mera et al. 2015; Quiroz y Sánchez 1997; Reccius 1983), la platería mapuche tiene su auge en el siglo XIX, en la Patagonia septentrional (Chile y Argentina). Esta evoluciona a partir del siglo XVIII a raíz de cambios estructurales dentro de la sociedad mapuche, como consecuencia del enriquecimiento progresivo de los líderes indígenas. El desarrollo del comercio transfronterizo conduce a un bienestar económico que permite el atesoramiento por parte de lonkos ${ }^{1}$ y ulmenes pudientes de monedas y producciones plateras, como aperos de montar y joyas femeninas (Aldunate del Solar 1983).

Las joyas de plata, de gran diversidad formal, conforman una de las producciones de mayor originalidad y prestigio desarrolladas tanto en Gulumapu (territorio mapuche del oeste) como en Puelmapu (territorio mapuche del este). La presencia de joyas de aleación de plata se extendió también a las Pampas argentinas, así como, a menor escala, al Centro y al Sur patagónicos. La platería indígena circuló intensivamente a través de las redes interétnicas que conectaban ambas vertientes de la cordillera de los Andes y que vinculaban los grupos de esta macrorregión: mapuche (pehuenche, huilliche, picunche, etc.), gunnuna kune (tehuelche septentrional), pampa, aonikenk (tehuelche meridional). Las fuentes evocan el comercio de joyas de plata de Chile hacia Argentina, aunque también hay constancia de un trabajo platero entre tehuelches, pampas y ranqueles (Mansilla

\footnotetext{
1 Unité Patrimoniale “Amériques”, Département Patrimoine et Collections, Musée du quai Branly, 222 rue de 1’Université, 75007 Paris cedex 07, Francia. pnr@quaibranly.fr

2 Archéologie des Amériques, UMR 8096 CNRS, MAE, 21 allée de l’Université, 92023 Nanterre, Francia. maria.guerra@ cnrs.fr
} 
1877; Musters 1964; Priegue 1996, 2007; Zeballos 1881). En las llanuras argentinas la platería estuvo relacionada con los aperos ecuestres, mientras que la joyería fue más importante en territorio chileno (Aldunate del Solar 2008).

Por su importancia material, ritual y simbólica, las joyas indígenas de Patagonia constituyen un archivo de primera importancia sobre el contexto social, económico y cultural de las sociedades que las produjeron. Sabemos por las fuentes que las alhajas eran de uso cotidiano y permanente, o ritual, y que evolucionaban en el tiempo a medida que la mujer alcanzaba la pubertad, se casaba y era madre (Lista 2006; Morris von Bennewitz 1997). La sacralidad de estas piezas estaba relacionada con su contenido informativo y el simbolismo del metal -la plata, lien, nacida de las lágrimas de la luna, küyen, y considerada como un mineral luminoso, protector y sanador que aporta sabiduría y fertilidad a quien lo lleva puesto- (Mora Penroz 1986). Los alfileres de pecho, los aros, los pectorales y los anillos protegían a la mujer y contribuían a definir y completar su estatus social.

El primer estudio sobre platería mapuche (Claude Joseph 1928) detalla las técnicas del orfebre mapuche, o retrafe, basándose en el testimonio de un artesano de los años 1920, quien había aprendido su oficio de un célebre retrafe de la segunda mitad del siglo XIX. Las publicaciones siguientes dan a conocer colecciones privadas y públicas; sus autores se focalizan en la descripción de una selección de piezas, evidenciando la gran diversidad formal de la joyería indígena (Housse 1939; Muthmann 1949 y 1958). En 1966, María Delia Millán de Palavecino anuncia el primer estudio comparativo de los fondos conservados en museos argentinos, chilenos y ginebrinos, procedentes de la Pampa, de la Patagonia septentrional y de la vertiente chilena de los Andes. Si bien este intento queda en estado de proyecto, el análisis preliminar de la autora abre la vía a los enfoques comparativos regionales y recalca la necesidad de un estudio del comercio de la platería, de las técnicas de fabricación y del oficio del platero.

El catálogo Platería Araucana (1983) del Museo Chileno de Arte Precolombino marca el inicio de los estudios especializados en el campo; en él Walter Reccius (1983) propone la primer clasificación de las joyas por siglo de producción (siglos XVIII-XX). Este trabajo es seguido en 1986 por otro catálogo de exposición, Tesoros de la Araucanía (Inostroza y Mora 1986), que incluye aportes significativos en los campos arqueológico, iconográfico y simbólico. Jorge Inostroza y Marco Sánchez ofrecen una primera presentación de joyas en contexto arqueológico, que evidencian la antigüedad del trabajo del metal en Araucanía. Zilez Mora Penroz contribuye con un estudio sobre el simbolismo de la plata y su relación al universo femenino y a las joyas. Los Plateros de la Frontera y la Platería Araucana (1997) es la tercera obra de referencia acerca de platería indígena de la Patagonia. Raúl Morris von Bennewitz hace un estudio detallado del informe del proceso de los ladrones presumidos del tesoro orfebre de un pudiente lonko (cacique) de la segunda mitad del siglo XIX, que le permiten precisar cómo eran atesoradas las joyas, su uso, así como la cantidad y el valor monetario de las piezas. El autor profundiza además en el análisis de la evolución cronológica de las joyas, proponiendo nuevos datos de la función, la decoración y el simbolismo de las alhajas femeninas. Desde el año 2000, el campo de la platería también ha movilizado a los coleccionistas privados (Caraballo de Quentín 2008; Dillehay 2009; Pereda 2002), quienes han propuesto presentaciones de sus fondos en el marco de exposiciones.

La publicación de los descubrimientos arqueológicos desde la década de 1980 (Berón 2010; Berón y González 2006; Hayduk 19811982; Inostroza y Sánchez 1986; Mera et al. 2015; Munita et al. 2009; Sánchez 1985) ha ampliado progresivamente el campo de conocimiento respecto del empleo y la antigüedad de estas piezas. Ciertas formas de joyas destacan por su permanencia desde los tiempos prehispánicos hasta el siglo XIX: el tири у un tipo de aro. En paralelo a estos trabajos, estudios más escasos han documentado el trabajo del metal entre los grupos tehuelches de la Patagonia septentrional (Priegue 1996, 2006) y meridional (Martinic 1995; Martinic y Prieto 1988).

Al día de hoy no existe ningún intento de cartografiar con precisión la producción joyera indígena que permita conocer los sitios y las condiciones de realización de las joyas en el siglo XIX. Los análisis de joyería se han centrado en los enfoques formales y estilísticos, partiendo de un corpus desprovisto del contexto de procedencia, sin tener en cuenta las características tecnológicas de las piezas. Uno de los objetivos de la investigación sobre el trabajo indígena del metal en la Patagonia conducida por el Musée du quai Branly (Paris) y el Centre National de la Recherche Scientifique (CNRS, 
Francia) es contribuir al estudio macrorregional de la platería indígena. En complemento a los trabajos existentes, nuestro proyecto apunta al estudio de la metalurgia indígena y al análisis físico-químico de las alhajas de plata. Nuestra propuesta inicial es partir del análisis de conjuntos de joyas contextualizados con precisión, que aunque no abarquen la totalidad de la gran variedad formal de la producción joyera indígena, permitan formular hipótesis precisas a su respecto.

Este artículo presenta los resultados preliminares obtenidos del estudio de las joyas de la colección La Vaulx conservada en París, de suma importancia por su información contextual y su diversidad tipológica. Esta colección platera se compone de aros, alfileres, punzones, anillos, elementos decorativos sueltos y agujas. Nos centramos en los aros de plata, por ser el conjunto de joyas más numeroso y de mayor diversidad tipológica y tecnológica que integra además ejemplares compuestos con elementos que podrían haber sido adjuntos en diferentes etapas de la vida de la joya.

Los objetos fueron seleccionados considerando que la finalidad del estudio es de elaborar un protocolo analítico para establecer criterios cronológicos relacionados con la fabricación de las piezas: la selección privilegió el aspecto del metal, el tipo de aro y la variedad formal dentro de cada tipo, las diferencias de acabado y de decoración. Con la muestra analizada se abordó la potencialidad de varias técnicas no destructivas accediendo a los detalles tecnológicos de las joyas y a la composición de sus aleaciones, buscando tanto los elementos mayoritarios como los minoritarios. De ese modo se optó por un estudio detallado de todas las partes de cada uno de los aros. Debido al tiempo de análisis, en particular aquel requerido para la determinación de los elementos minoritarios por técnicas basadas en aceleradores de partículas, fue necesario elegir en algunos casos un solo aro de cada par. El corpus final analizado fue de 32 aros (19 pares y 13 aros sueltos).

\section{Los Adornos de Plata de la Colección La Vaulx, Paris}

\section{La Colección Henry de La Vaulx}

El Musée du quai Branly parisino conserva una colección de platería reunida por el conde Henry de La Vaulx en el marco de una misión a Patagonia en
1896-1897. Este viaje de exploración tenía como principal objetivo la recolección de osamentas que permitieran el estudio de las razas patagónicas. Adicionalmente, el Musée d'Ethnographie du Trocadéro de Paris también le encargó a La Vaulx la adquisición de piezas representativas de las culturas indígenas contemporáneas, anheladas en Francia para estudios de tecnología comparada. La Vaulx constituyó una importante colección de pieles pintadas, textiles y materias primas, objetos de la vida cotidiana y joyas de plata (Núñez-Regueiro y Vezub 2012). Estas últimas fueron principalmente obtenidas en 1896 en la toldería de Valentín Saygüeque (1830-1903), establecida sobre el río Chubut a más de quinientos kilómetros de la territorialidad original del cacique (La Vaulx 1901:128). Saygüeque, famoso por el tesoro monetario y platero acumulado antes de su derrota militar en 1882 (Musters 1964:320), había encabezado durante dos décadas (1860-1881) un grupo de orígenes mixtos huilliche, pehuenche, pampa y tehuelche que controlaba los pasos cordilleranos y el "País de las Manzanas" (Vezub 2009), ubicado al norte del lago Nahuel Huapi sobre la vertiente oriental de la cordillera de los Andes, en el sur de la provincia de Neuquén (Figura 1). La colección platera que La Vaulx obtiene para las colecciones nacionales francesas sobresale por el número importante de piezas (130), así como por el valor económico y simbólico que conforma $(2,3 \mathrm{~kg})$.

Esta colección es extremadamente interesante por su homogeneidad tipológica. Entre las formas tradicionales podemos citar tири о "alfileres de pecho" empleados para sujetar las capas femeninas; aros de forma rectangular (Figuras 2-4) y discoidal (Figuras 5-7); anillos con chatón circular o floral; elementos de pectoral con figuración antropomorfa; colgantes sueltos de formas diversas, que servían para la confección de pectorales. La colección platera se caracteriza también por la presencia de aros de forma anular con motivo perlado (Figuras 8-10) y katahue o punzones así como agujas de plata ${ }^{2}$.

\section{Los aros de la toldería del cacique Saygüeque}

La colección La Vaulx incluye tres tipos de aros que presentan características formales y usos diferenciados: los aros rectangulares (o trapezoidales) denominados chahuay-chapel o upül, los aros o chahuay de forma discoidal, y los aros de forma anular perlada. 


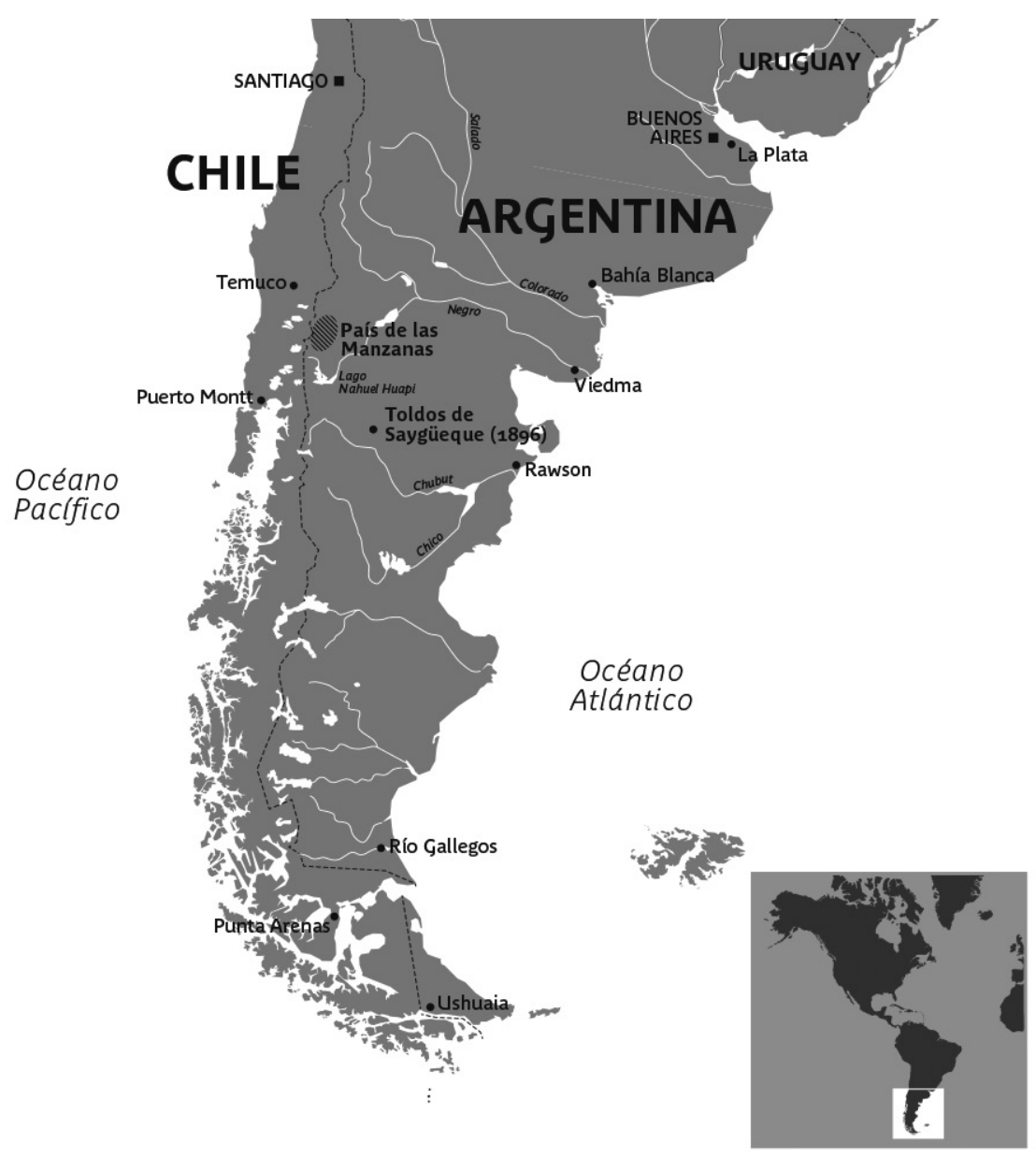

Figura 1. Mapa de la región considerada: el País de las Manzanas y la toldería del cacique Saygüeque en la provincia del Chubut (1896).

Map of the study region: the Land of the Apples and Saygüeque's camp in the Chubut province.

Los aros rectangulares (o trapezoidales) denominados chahuay-chapel o upül ${ }^{3}$ (Figuras 2 a 4), de uso ceremonial, eran lucidos por la mujer indígena en ocasiones festivas o en ceremonias de carácter ritual (Morris von Bennevitz 1997:73). Es una forma de gran antigüedad en la Araucanía chilena, con antecedentes en cobre desde el siglo XII (Campbell 2004:83, 89; Inostroza y Sánchez 1986; Mera et al. 2015; Munita et al. 2010). En la sociedad tehuelche los aros de forma rectangular eran más específicamente reservados a la hija primogénita (Priegue 1996:66). Su tamaño, que podía exceder los $10 \mathrm{~cm}$ de ancho, así como su pulido y resplandor, ponían énfasis en su valor simbólico. Su decoración es generalmente limitada. Los ejemplares de la colección La Vaulx, 21 pares y dos aros sueltos, miden entre 4,5 y $16,4 \mathrm{~cm}$ de ancho, y solo dos de ellos presentan motivos decorativos (Figura 4). Para este estudio analizamos ocho pares de aros y dos ejemplares sueltos.

Los aros o chahuay de forma discoidal (Figuras 5 a 7), los "más comunes entre los Mapuche" (Claude Joseph 1928), eran "de uso cotidiano y permanente" (Morris von Bennevitz 1997:74). Estas joyas estaban vinculadas a su propietaria, presentando en sus calados y decoración hechos relacionados con ella, o con su vida, dejando suponer que los aros podían evolucionar en su forma o decoración, o bien ser reemplazados, a lo largo de la vida de la mujer. Entre los tehuelches, también se emplean estos "aros sencillos [...] más chicos, redondos" (Priegue 2007:76). En la 


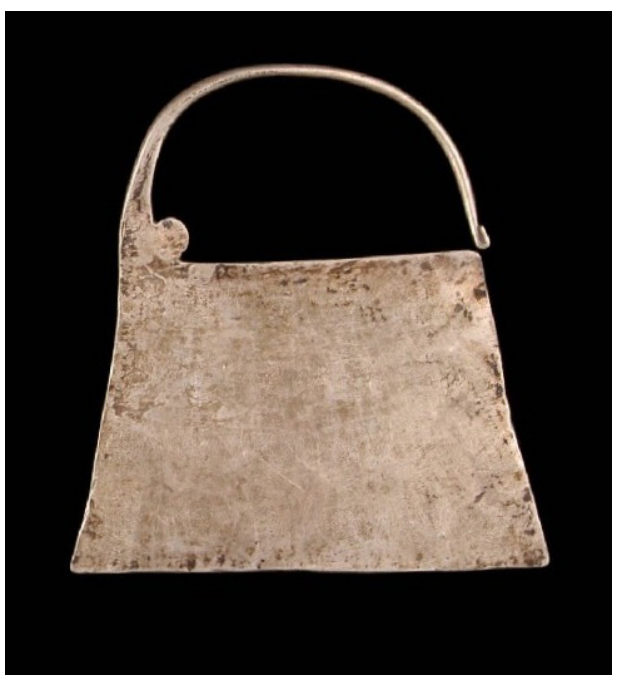

Figura 2. Aro upül, aleación de plata (altura: 10,2 cm), Musée du quai Branly, $\mathrm{n}^{\circ}$ inv. 71.1898.59.127.1 @ Musée du quai Branly. Upül earring, silver alloy (high: $10.2 \mathrm{~cm}$ ), Musée du quai Branly, ref. 71.1898.59.127.1 @ Musée du quai Branly.

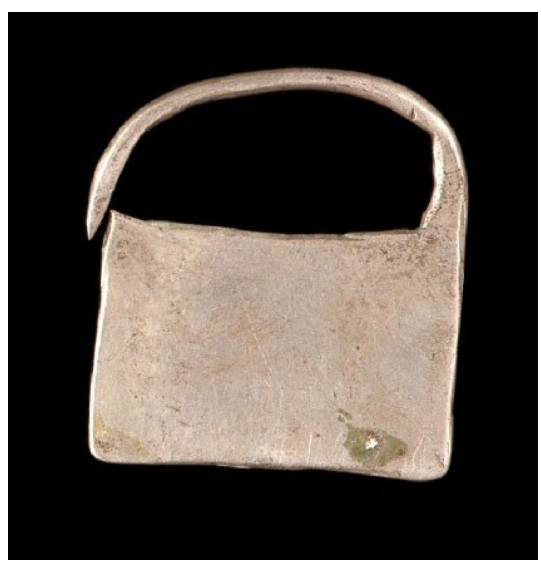

Figura 3. Aro upül, aleación de plata (altura: 6,6 cm), Musée du quai Branly, $\mathrm{n}^{\circ}$ inv. 71.1898.59.109.1 @ C Musée du quai Branly. Upül earring, silver alloy (high: $6.6 \mathrm{~cm}$ ), Musée du quai Branly, ref. 71.1898.59.109.1 @) Musée du quai Branly.

colección La Vaulx, que cuenta con cinco pares y 21 aros sueltos, se pueden distinguir tres grupos de aros dentro de este tipo: (1) los más pequeños, sin calado y con una limitada decoración (Figura 5), que miden entre 2,2 y 2,7 cm de alto; (2) aquellos más grandes con calado y decoración (Figura 6), de dimensiones comprendidas entre 2,6 y $3,8 \mathrm{~cm}$; (3) los mayores, con uno o dos calados, decoración, y una a tres placas circulares o romboidales unidas al cuerpo de la joya por anillos metálicos (Figura 7), que miden de 3 a $6,3 \mathrm{~cm}$. Hemos analizado seis

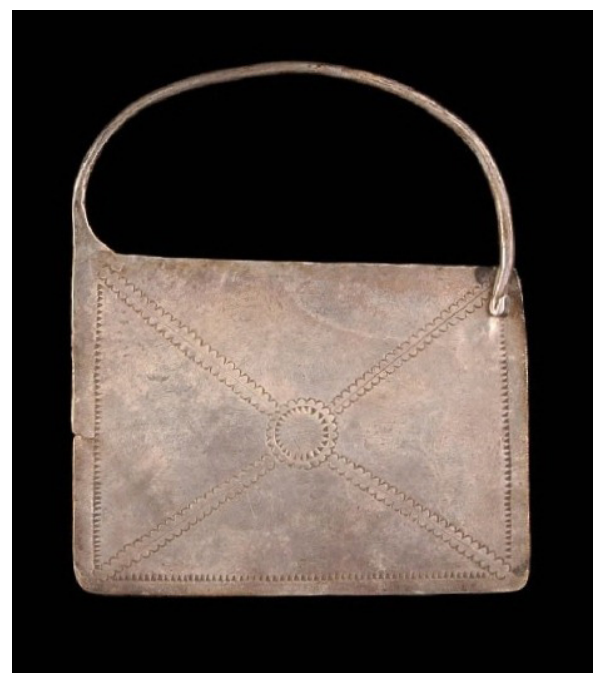

Figura 4. Aro upül con decoración incisa, aleación de plata (altura: 8,1 cm), Musée du quai Branly, $\mathrm{n}^{\circ}$ inv. 71.1898.59.130.1 (C) Musée du quai Branly.

Upül earring with incised decoration, silver alloy (high: 8.1 cm), Musée du quai Branly, ref. 71.1898.59.130.1 (C) Musée du quai Branly.

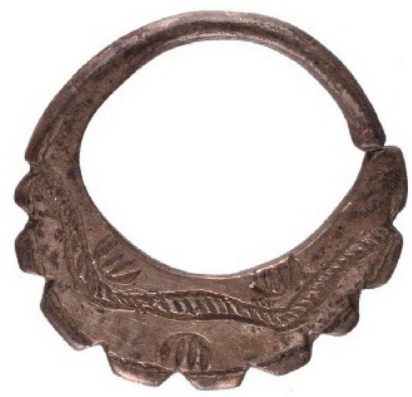

Figura 5. Aro chahuay discoidal, aleación de plata (altura: 2,3 cm), Musée du quai Branly, nº inv. 71.1898.59.77 (C) Musée du quai Branly.

Discoidal chahuay earring, silver alloy (high: $2.3 \mathrm{~cm}$ ), Musée du quai Branly, ref. 71.1898.59.77 (C) Musée du quai Branly.

de los primeros (un par y cuatro sueltos), cuatro de los segundos (sueltos) y cuatro de los terceros (un par y dos sueltos).

El tercer tipo, el aro o chahuay anular perlado (Figuras 8 a 10), no ha sido considerado en las tipologías recientes de platería mapuche. Sin embargo, a pesar de su rareza en las colecciones que han llegado hasta nosotros se presentan como una forma establecida en la Patagonia. Así lo sugieren, para el centro-sur de Chile, los testimonios del naturalista Claude Gay, quien 


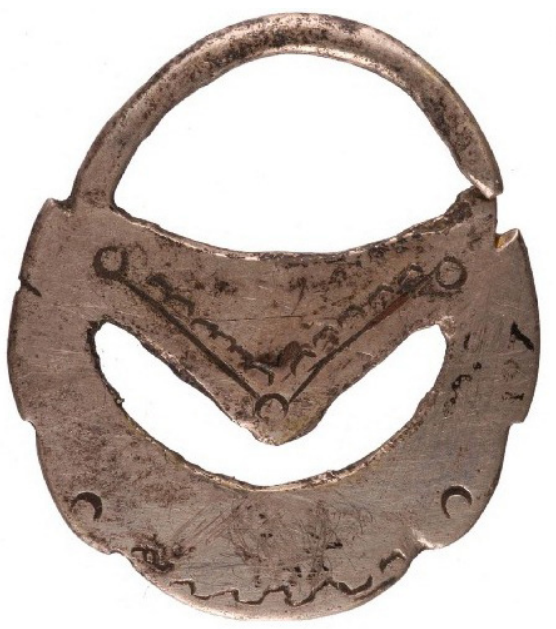

Figura 6. Aro chahuay discoidal con calado, aleación de plata (altura: 3,1 cm), Musée du quai Branly, nº inv. 71.1898.59.69 (C) Musée du quai Branly.

Discoidal chahuay earring with openwork, silver alloy (high: $3.1 \mathrm{~cm})$, Musée du quai Branly, ref. 71.1898.59.69 (C) Musée du quai Branly.

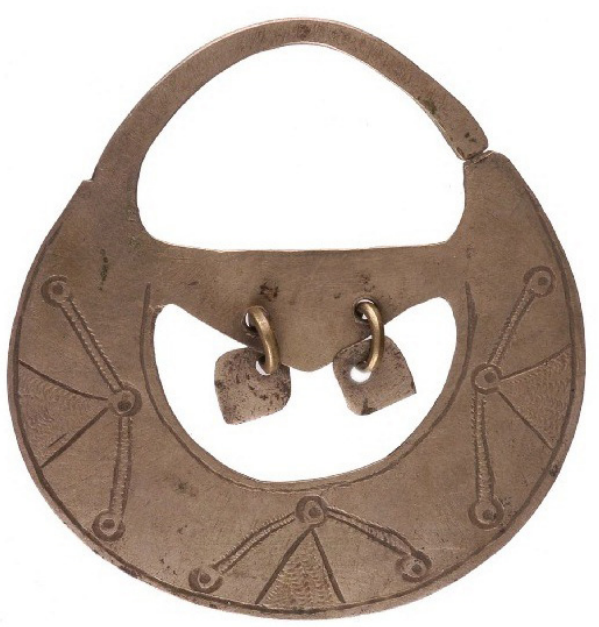

Figura 7. Aro chahuay discoidal con calado y dos placas romboidales suspendidas por anillos metálicos, aleación de plata (altura: 6,3 cm), Musée du quai Branly, $\mathrm{n}^{\circ}$ inv. 71.1898.59.64 (C) Musée du quai Branly.

Discoidal chahuay earring with openwork and two pendant sheets suspended by metallic rings, silver alloy (high: $6.3 \mathrm{~cm}$ ), Musée du quai Branly, ref. 71.1898.59.64 (C) Musée du quai Branly.

incluye en sus archivos un dibujo de aro anular con perlas, fechado a mediados del siglo XIX (Diego Milos, comunicación personal 2012), y aquel de Claude Joseph, que en su estudio sobre la platería araucana incorpora "el chahuay de forma anular [cuya] mitad inferior maciza toma

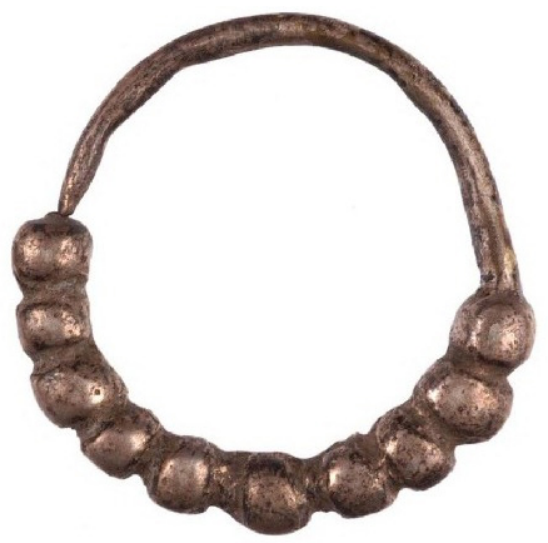

Figura 8. Aro anular, aleación de plata (altura: $3,4 \mathrm{~cm}$ ), Musée du quai Branly, n inv. 71.1898.59.88.1 @ Musée du quai Branly. Annular earring, silver alloy (high: $3.4 \mathrm{~cm}$ ), Musée du quai Branly, ref. 71.1898.59.88.1 () Musée du quai Branly.

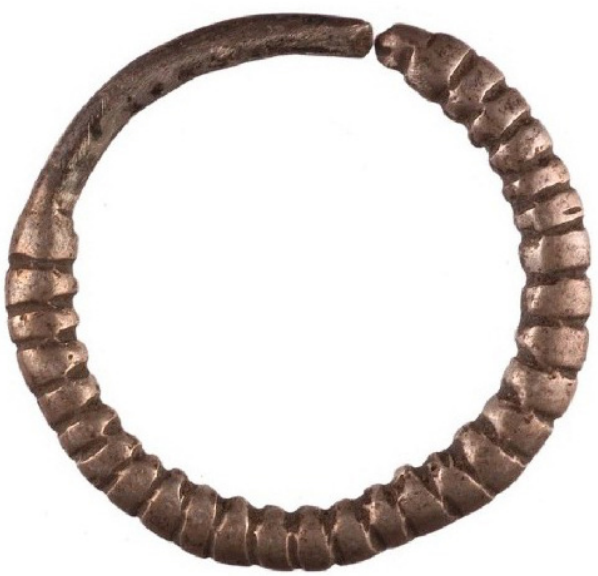

Figura 9. Aro anular, aleación de plata (altura: $3,8 \mathrm{~cm}$ ), Musée du quai Branly, n inv. 71.1898.59.94.1 @ Musée du quai Branly. Annular earring, silver alloy (high: $3.8 \mathrm{~cm}$ ), Musée du quai Branly, ref. 71.1898.59.94.1 @ Musée du quai Branly.

el aspecto de un rosario por la conjunción de una serie de tuberculitos esféricos" (Joseph 1930: fig. 9). Georg Schythe también obtiene piezas similares en el extremo-sur patagónico, en Punta Arenas, en 1853-1865 (Hartmann 1974: fig. 64-69). Esta forma parece haber sido de uso cotidiano aunque menos común, y no exclusivo de las mujeres: el listado de la colección berlinesa asocia esta forma de aro con el ajuar femenino, pero especifica: "también en uso entre los hombres" 4 . La colección parisina incluye cinco pares y tres aros sueltos de este tipo, de 2,6 a 6,0 cm de diámetro, de los cuales hemos analizado tres pares y un ejemplar suelto, que integra una llanka o cuenta de piedra (Figura 10). 


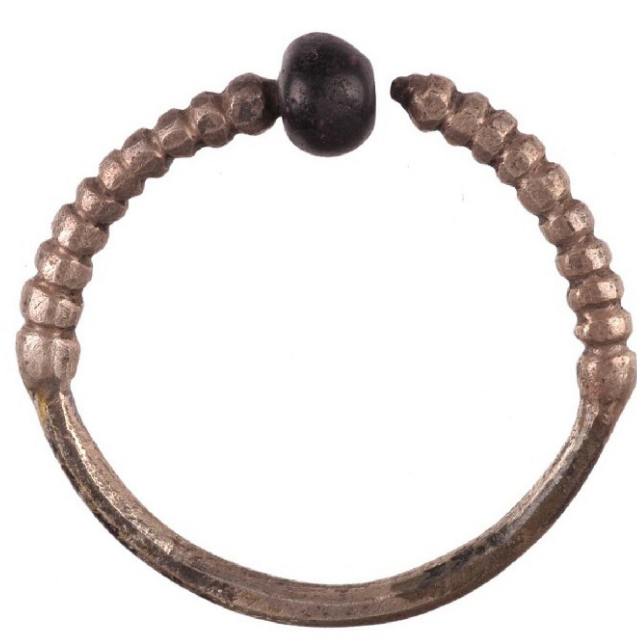

Figura 10. Aro anular, aleación de plata (altura: $4,2 \mathrm{~cm}$ ), Musée du quai Branly, $\mathrm{n}^{\circ}$ inv. 71.1898.59.90 @ Musée du quai Branly Annular earring, silver alloy (high: $4.2 \mathrm{~cm}$ ), Musée du quai Branly, ref. 71.1898.59.90 (C) Musée du quai Branly.

\section{Tecnología y Artesanos}

El conjunto de joyas homogéneo y proveniente de una misma toldería sugiere varias interrogantes. En primer lugar el saber si esta homogeneidad en la tipología se observa también en la tecnología y en la materia prima empleadas, así como en la calidad de ejecución de las piezas. El análisis preliminar de los aros de la colección realizados por microscopia óptica, SEM y radiografía (Guerra 2008) muestra que las piezas fueron producidas principalmente por fundición y por martillado, recorte, perforación y pulido. Los motivos decorativos, generalmente en cincelado, corresponden a una simple sucesión de marcas realizadas por golpe con una pequeña variedad de cinceles y punzones de formas simples y variadas.

El análisis detallado de la muestra evidencia sin embargo una calidad de factura múltiple pero relacionada con el tipo de aro considerado: a pesar de un trabajo de fundición y de martillado bastante homogéneo, la decoración de los aros upül es de mejor calidad que la de los aros discoidales o anulares. En esta producción se observa una gran variedad de manos: las marcas de herramientas difieren en forma, regularidad y tamaño. No se observó en ninguna ocasión la mano de un mismo artesano en diferentes joyas, a excepción de los componentes de cada par de aros.

En el caso de los chahuay discoidales, el cuerpo de la joya en los ejemplares simples (grupos 1 y
2) y en los compuestos (grupo 3) es generalmente obtenido martillando un lingote, que es luego recortado para darle la forma discoidal requerida e integrar eventualmente la o las placas de suspensión. Sin embargo, en algunos casos el cuerpo de la joya se obtuvo simplemente por fundición. Aquí, el cuerpo presenta a menudo un borde aserrado por recorte (Figura 5). Sin embargo, la decoración cincelada de estos aros es generalmente de ejecución grosera, en marcado contraste con la habilidad requerida para una metalurgia por fundición, o a la capacidad de darle al cuerpo de la pieza una forma armoniosa por recorte y cincelado. La destreza y la habilidad del artesano (la seguridad de ejecución de su trabajo) son visibles en el resultado de los golpes de cincel o de punzón aplicados para producir el motivo decorativo. Aquí las marcas de cinceles o punzones son burdas y poco regulares, realizadas con poca fuerza y firmeza, a veces con errores en la ejecución de los motivos, sugiriendo una mano inexperta, con poca costumbre de este tipo de trabajo (Figura 11). La irregularidad de la decoración de ciertos aros comparada con el trabajo homogéneo y regular de otros lleva a pensar que ciertas joyas fueron decoradas por un orfebre profesional (platero) y otras por personas que, aunque posiblemente controlaran el proceso metalúrgico, no tenían experiencia en la ejecución del grabado y del cincelado.

En lo que se refiere a los chahuay anulares, tanto los chicos (Figura 8) como los grandes (Figura 9) fueron obtenidos a partir de la confección de un molde. Sin embargo, solo los de mayor tamaño fueron fundidos y luego finalizados por un trabajo de cincelado superficial que permitió precisar la forma de los motivos de perlas (Figura 9). En estos aros la calidad de ejecución es relativamente homogénea, aunque se trata también de un conjunto con menor representatividad, por ser el más restringido numéricamente.

En cuanto a los aros upül fueron obtenidos por martillado, recortados con cincel y finalizados por pulido. Si bien en este grupo también se observan diferencias en la calidad de ejecución de los aros, es importante recalcar que la factura de las piezas es aun de mucho mejor nivel. El par más tosco (Figura 3) está constituido de ejemplares pequeños recortados pero no pulidos. Sin embargo, los aros upül de la colección son generalmente de forma equilibrada, con un arco de suspensión fino y alguna que otra vez una protuberancia semicircular al pie del arco. 

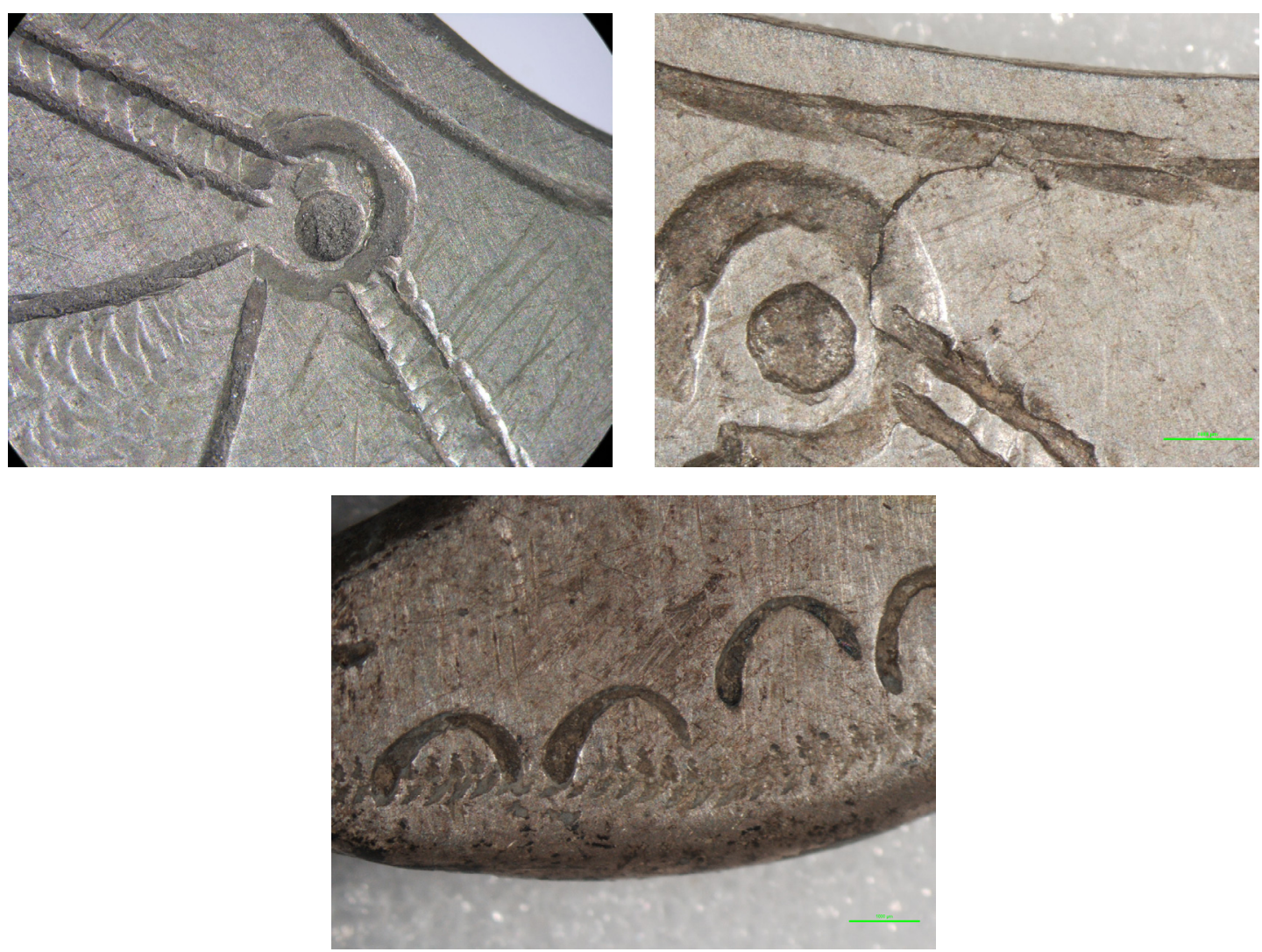

Figura 11. Detalles por microscopia óptica de los motivos de los aros chahuay, Musée du quai Branly, $\mathrm{n}^{\circ}$ inv. 71.1898.59.64 y 71.1898.59.83.1 @ D. Bagault, C2RMF. Los motivos decorativos son irregulares, sin líneas incisas de diseño previo, hechos con uno o dos cinceles: círculo mal estampado (izquierda), motivo del borde irregular y con marcas sobrepuestas (centro), motivos mal alineados (derecha).

Decoration details under the stereomicroscope of chahuay earrings Musée du quai Branly, ref. 71.1898.59.64 and 71.1898.59.83.1 (C) Musée du quai Branly. The motifs are irregular, made without inscribed lines, by using one or two chisels: badly elaborated circle (left), untidy overlapping border motif (centre), misaligned motif.

Los upül del par $\mathrm{n}^{\circ} 130$ (Figuras 4 y 12) son joyas de una calidad fuera de lo común, ejecutadas por un platero profesional.

\section{El Origen y el Valor del Metal: Las Aleaciones de Plata}

La segunda cuestión planteada por el conjunto de joyas obtenido por La Vaulx concierne a la materia prima empleada en la realización de las joyas. Si bien las fuentes históricas y etnográficas evocan la existencia de minas explotadas por los indígenas, al día de hoy ninguna de ellas ha sido localizada. Se sabe que la mayor parte de las piezas del siglo XIX era manufacturada a partir de monedas, a veces por simple aplicación directa, como lo evidencia un anillo de la colección La Vaulx cuyo chatón fue realizado con una moneda argentina de diez centavos. La utilización de monedas evita el trabajo de ejecución de la aleación, una etapa larga y costosa. Si se considera el peso y el tamaño de los aros considerados en este estudio, los chahuay discoidales de los grupos 1 y 2 (simples) podrían haber sido obtenidos por recorte de monedas; en cambio, los aros del grupo 3 (compuestos) así como una mayoría de aros upül superan por su peso el de una moneda. Se sabe que la masa metálica noble podía ser incrementada adicionando otros metales, de orígenes variados, provenientes por ejemplo de objetos hispano-criollos (Sánchez 1985), y que el latón fue ampliamente utilizado por los grupos tehuelches. La tonalidad variada del metal empleado 

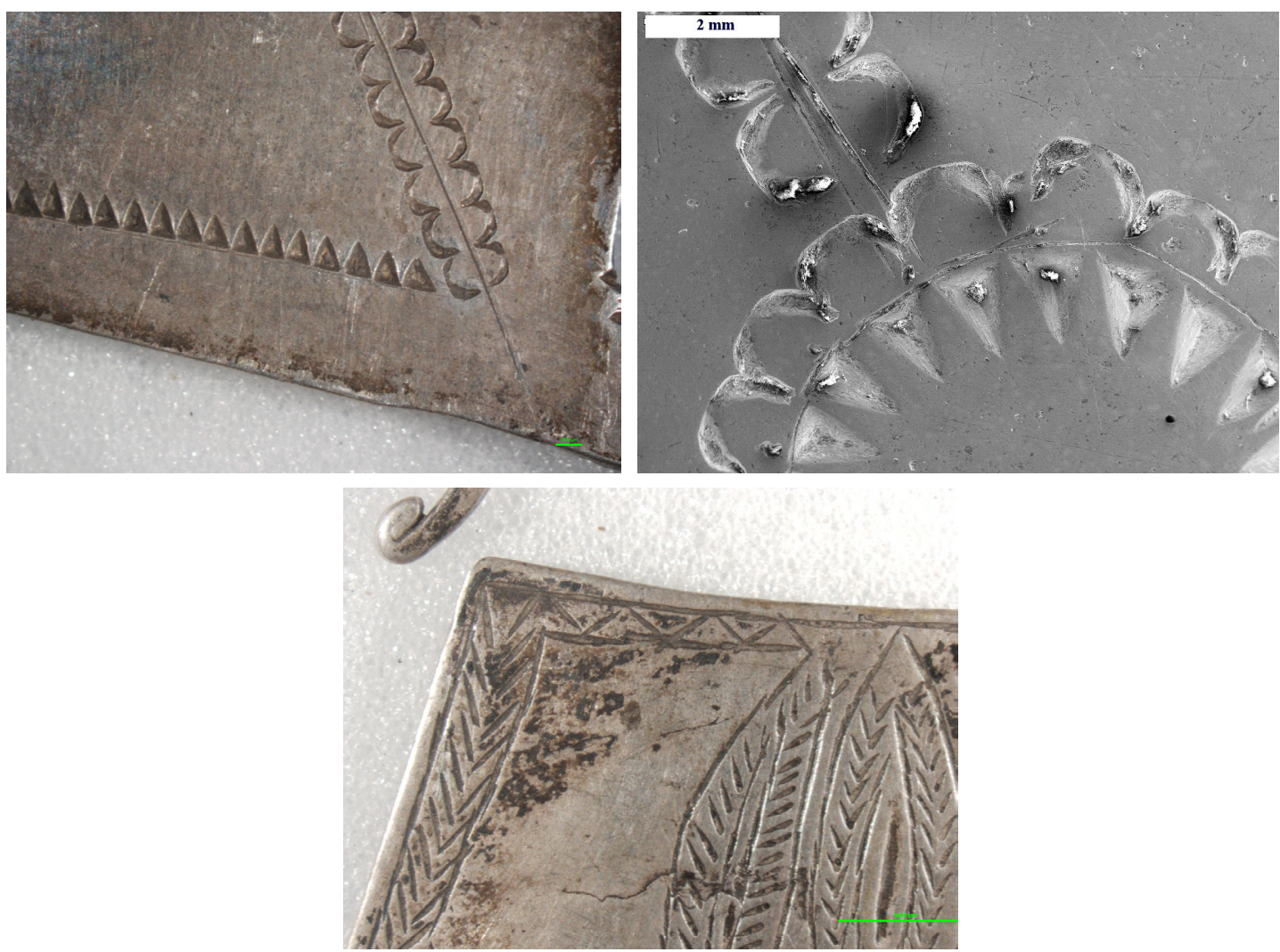

Figura 12. Detalles de los motivos de los aros upül por microscopia óptica, Musée du quai Branly, $\mathrm{n}^{\circ}$ inv. 71.1898.59.130.1 y 71.1898.59.108 @ D. Bagault, C2RMF. El aro 130 (izquierda) presenta una decoración muy regular con punzones variados; se observan líneas incisas para guiar la mano del artesano y asegurar la regularidad del motivo (visible en el SEM como muestra la imagen central). El aro 108 (derecha) fue decorado con un único cincel, sin diseño previo del motivo: la irregularidad final del motivo es evidente. El aro 130.1 casi no presenta huellas de uso, mientras que el aro 108 está muy gastado.

Decoration details under the stereomicroscope of upül earrings Musée du quai Branly, ref. 71.1898.59.130.1 and 71.1898.59.108 (C) Musée du quai Branly/C2RMF. Earring 130 (left) shows a regular decoration with different chisels, as well as inscribed lines meant to guide de craftsman's hand and ensure the regularity of the final motif (visible under the SEM in the central image). Earring 108 (right) was decorated with a single chisel, without previous layout by inscribed lines: the final motif is irregular. Earring 130 has almost no sign of use-wear, whilst earring 108 is very worn-out.

en la confección de las joyas de la colección La Vaulx sugiere el uso de aleaciones metálicas diferentes. Resultó interesante identificar esas composiciones para analizar el valor económico y simbólico de las joyas, e intentar encontrar criterios cronológicos relacionados con los posibles cambios de aleaciones.

Los análisis de composición fueron realizados por PIXE (del inglés particle induced X-ray emission) con un haz de protones de $3 \mathrm{MeV}$ y $50 \mu \mathrm{m}$ de diámetro (Guerra 2011; Guerra y Tissot 2013) en el acelerador AGLAE del Centre de Recherche et de Restauration des Musées de France, en Paris. Los resultados muestran que las piezas se produjeron en aleaciones de plata de calidad variable, constituidas de diferentes elementos. La Tabla 1 presenta los resultados obtenidos para los tres tipos de aros; en lo que se refiere a los chahuay discoidales compuestos solo se consideró el cuerpo del aro (sin las placas ni los anillos de suspensión). En la Figura 13 se representan las concentraciones de plata y cobre obtenidas para los aros por tipo. Lo que resalta a primera vista es que los aros upül son los únicos que presentan una aleación de mejor calidad y más constante, con un alto porcentaje de plata contenido entre 76 y $92 \%$. Los dos otros tipos de aros tienen un tenor en plata por lo general inferior, en una gama entre 59 y $88 \%$ en el caso de los aros discoidales, y 74 y $84 \%$ en el de los aros anulares. 
Tabla 1. Aleaciones obtenidas por PIXE con un haz de protones de $3 \mathrm{MeV}$ para las piezas analizadas. Composition of the alloys obtained by PIXE with a beam of $3 \mathrm{MeV}$ protons for the analysed earrings.

\begin{tabular}{cccccc}
\hline \multicolumn{7}{c}{$\mathrm{Ag} \%$} & $\mathrm{Cu} \%$ & $\mathrm{Zn} \%$ & $\mathrm{Ni} \%$ & $\mathrm{~Pb} \%$ \\
\hline \multicolumn{7}{l}{ Chahuay discoidal grupo 1 } \\
\hline 74 & 81,5 & 17,9 & 0,0 & 0,0 & 0,3 \\
77 & 75,5 & 15,1 & 8,4 & 0,0 & 0,4 \\
80 & 87,9 & 11,4 & 0,1 & 0,0 & 0,2 \\
81 & 71,5 & 26,2 & 1,5 & 0,3 & 0,3 \\
$83 \_1$ & 64,2 & 32,5 & 1,0 & 0,2 & 1,4 \\
$83 \_2$ & 69,3 & 28,5 & 0,8 & 0,7 & 0,3 \\
\hline
\end{tabular}

Chahuay discoidal grupo 2

$\begin{array}{llllll}69 & 77,7 & 20,8 & 0,7 & 0,3 & 0,2 \\ 70 & 86,9 & 12,6 & 0,1 & 0,0 & 0,2 \\ 73 & 82,2 & 17,1 & 0,1 & 0,0 & 0,4 \\ 76 & 77,2 & 19,3 & 2,9 & 0,1 & 0,3\end{array}$

\begin{tabular}{cccccc}
\hline \multicolumn{6}{c}{ Chahuay discoidal grupo 3} \\
63 & 70,5 & 28,8 & 0,3 & 0,1 & 0,2 \\
64 & 59,2 & 34,8 & 3,5 & 1,9 & 0,2 \\
$65 \_1$ & 67,4 & 28,1 & 3,2 & 0,1 & 0,6 \\
$65 \_2$ & 69,6 & 25,7 & 3,3 & 0,1 & 0,6 \\
$66 \_2$ & 73,9 & 25,0 & 0,3 & 0,1 & 0,2 \\
$66 \_1$ & 79,8 & 18,5 & 0,7 & 0,1 & 0,4 \\
\hline Chahuay anular & & & & \\
$88 \_1$ & 80,0 & 17,2 & 2,2 & 0,1 & 0,4 \\
$88 \_2$ & 77,6 & 19,7 & 1,7 & 0,3 & 0,4 \\
90 & 83,5 & 15,4 & 0,3 & 0,0 & 0,3 \\
$93 \_1$ & 79,0 & 20,0 & 0,3 & 0,0 & 0,3 \\
$93 \_2$ & 77,3 & 22,0 & 0,2 & 0,0 & 0,3 \\
$94 \_1$ & 74,3 & 23,2 & 1,2 & 0,3 & 0,5 \\
$94 \_2$ & 68,8 & 28,6 & 1,4 & 0,3 & 0,4 \\
\hline Upül & & & & & \\
$109-1$ & 76,4 & 22,8 & 0,2 & 0,1 & 0,2 \\
$110-1$ & 82,6 & 15,7 & 0,8 & 0,1 & 0,1 \\
$111-1$ & 78,8 & 20,5 & 0,9 & 0,0 & 0,2 \\
$118-1$ & 86,3 & 13,4 & 0,0 & 0,0 & 0,1 \\
$119-1$ & 82,5 & 16,6 & 0,3 & 0,1 & 0,2 \\
$121-1$ & 81,2 & 17,7 & 0,5 & 0,1 & 0,2 \\
$127-1$ & 77,5 & 21,9 & 0,2 & 0,0 & 0,2 \\
$130-1$ & 91,7 & 7,4 & 0,0 & 0,0 & 0,0 \\
\hline
\end{tabular}

El elemento que completa la aleación es típicamente el cobre, pero en algunos casos también el zinc, cuyo tenor puede alcanzar el 10\% en los aros considerados en este trabajo. La presencia de este elemento podría estar relacionada con la utilización no de cobre pero de latón. No obstante, la cantidad de zinc está relacionada con un aumento del tenor en níquel. Esta presencia indica el empleo de aleaciones de plata y de aleaciones de cobre-níquel-zinc (por su color son denominadas en francés cobre blanco, y en alemán nueva plata), de coloración plateada y brillante cuyo empleo se desarrolló a partir de mediados del siglo XIX. Producidas en Europa, esas aleaciones fueron comercializadas en América, y empleadas en producciones que imitaban la plata. Las aleaciones cobre-níquel-zinc (Cu-Ni-Zn), con excelentes cualidades dúctiles en frío, fueron así introducidas progresivamente en la fabricación de monedas. Estas permitieron el incremento de la masa monetaria de "plata", conservando el aspecto del metal preciado y reduciendo considerablemente los costos. En Chile y Argentina las monedas fueron acuñadas en aleaciones de cobre-níquel-zinc a partir de 1871 y 1896 (Auer 2001).

La Figura 14 presenta el tenor en níquel y zinc en función del tenor en cobre de las piezas analizadas. Se observa que la mitad de las piezas contiene pequeñas cantidades de níquel y zinc. Aun así, el tenor en zinc en los aros upül es siempre inferior a $1 \%$, lo cual indica que no fueron empleadas en su confección aleaciones de $\mathrm{Cu}-\mathrm{Zn}$-Ni. En los otros dos tipos de aros, los aros discoidales y anulares, la ausencia y presencia de esas aleaciones se observa en proporciones equivalentes, sugiriendo un uso indiscriminado de la masa metálica a disposición. Se observa también que los upül y los aros anulares se encuentran casi todos concentrados en un solo grupo químico.

La identificación de las aleaciones $\mathrm{Cu}-\mathrm{Zn}-\mathrm{Ni}$ en los aros muestra que es posible basarse en la presencia de zinc y de níquel para inferir no solo la naturaleza de la materia prima empleada, sino también el período de fabricación de las joyas. Las monedas chilenas en cuproníquel anteriores a 1896 contienen diferentes concentraciones de cobre, níquel y zinc: Cu75-Ni25, Cu65-Zn25-Ni10, Cu60-Zn25Ni15, Zn15-Ni15 y Cu70-Zn10-Ni20 (Auer 2001) Algunos aros de la colección contienen aleaciones cuyas relaciones $\mathrm{Ni} / \mathrm{Zn}$ corresponden a estas monedas: los aros discoidales $n^{\circ} 69$ y n $^{\circ} 63$, y el upül $n^{\circ} 109-1$ presentan la proporción Cu65-Zn25-Ni10; el aro discoidal $n^{\circ}$ 64, aquella Cu60-Zn25-Ni15. Se puede evaluar la composición de la aleación de plata de "base" (que puede corresponder a la aleación de las monedas estudiadas en Guerra 2000 y 2004), retirando la "parte" en cuproníquel añadida por adición de aquellos tipos de monedas. Procediendo de esta manera se obtienen las siguientes composiciones de aleaciones de plata originales: Ag81,2-Cu18,8 para el aro $n^{\circ} 69, \mathrm{Ag} 73,3-\mathrm{Cu} 26,7$ para el aro $n^{\circ} 64$, Ag71,9-Cu28,1 para el aro n ${ }^{\circ} 63$ y Ag77,8-Cu22,2 para el aro $\mathrm{n}^{\mathrm{o}} 109-1$. En un trabajo anterior centrado 


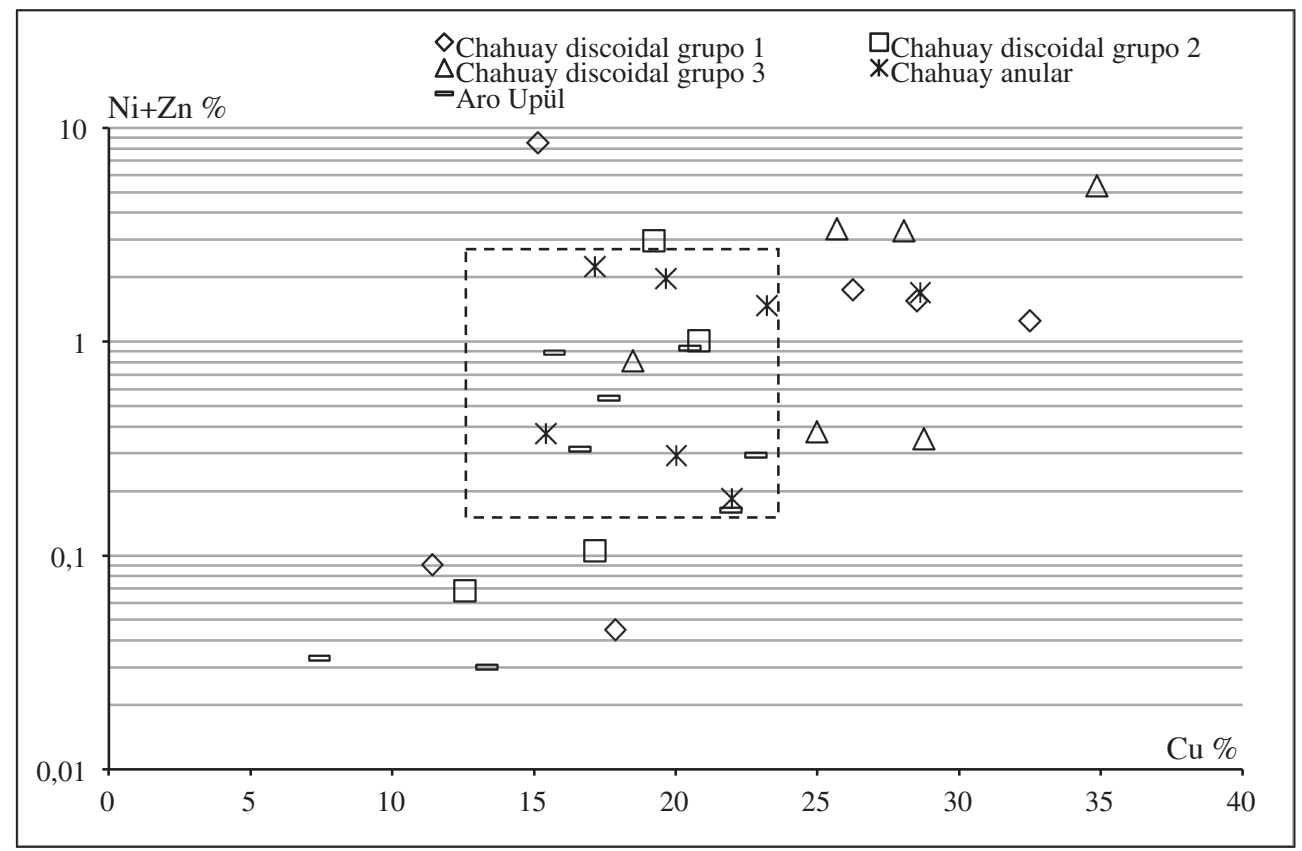

Figura 13. Representación del tenor de plata y cobre en la muestra analizada, por tipos de aros. Representation of the silver and copper contents in the analyzed earring, by types.

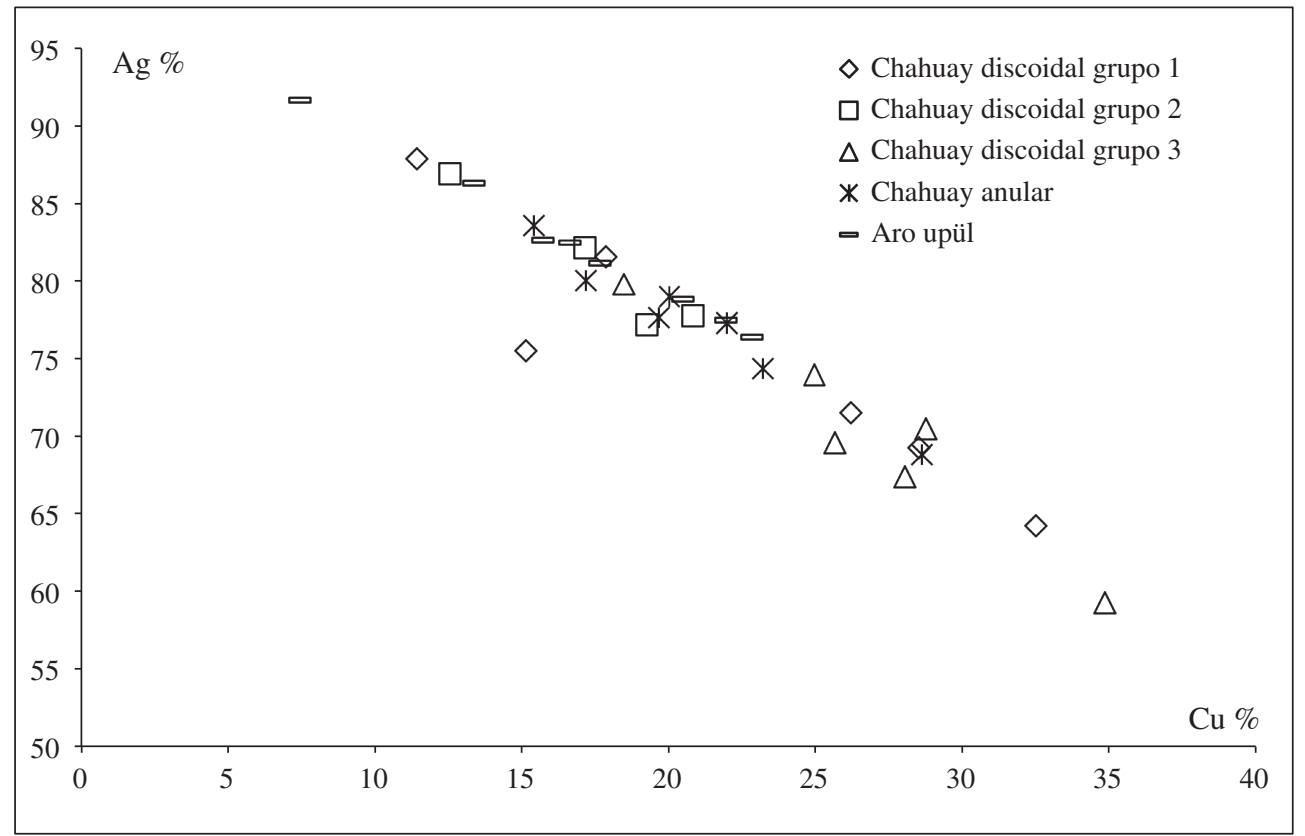

Figura 14. Representación del tenor en Ni y Zn en función del tenor de Cu en la muestra analizada, por tipos de aros. Representation of the niquel and zink contents in function of the Cu contents in the analyzed earrings, by types.

sobre los chahuay de forma discoidal compuestos se puso en evidencia que todas las placas decorativas y los anillos de suspensión de los ejemplares de la colección están realizados en aleaciones metálicas distintas de aquellas empleadas para la confección del cuerpo de las joyas; en el caso del aro ${ }^{\circ} 66-2$, 
se pudo mostrar que las placas suspendidas fueron añadidas posteriormente a la decoración del cuerpo del aro (Guerra y Núñez-Regueiro 2012). La aleación de una de sus placas decorativas corresponde a la de la moneda chilena Cu70-Zn10-Ni20. En este caso, retirando la cantidad así añadida de cobre, la aleación de plata original sería de Ag76,1-Cu23,9, que corresponde también a la aleación empleada para la fabricación del cuerpo del aro.

\section{Lo que Cuentan los Aros: Discusión a Partir del Análisis de la Colección La Vaulx}

La colección La Vaulx ofrece un conjunto homogéneo de joyas, obtenidas por trueque con las mujeres de los toldos de Saygüeque, quince años después de la derrota militar del cacique. Si se compara este conjunto con la producción que se conoce de la zona patagónica-pampeana, es notorio el número limitado de tipos de joyas que obtiene el explorador, quedando el interrogante de si este refleja con exactitud el panel de joyas en uso en la toldería o si resulta simplemente del azar de la recolección etnográfica. La gran uniformidad formal de este conjunto y la presencia marcada de dos tipos de piezas poco comunes en colecciones de otras regiones -el chahuay anular perlado y el katahue con cabeza circular y apéndices curvos-nos hace inclinar por la primera opción. El análisis contextual de la misión a Patagonia de La Vaulx, que evidenció una metodología de colecta orientada hacia la variedad tipológica y la exhaustividad (Núñez-Regueiro y Vezub 2012), también avalaría esta hipótesis.

Partiendo del postulado de que la colección reúne un conjunto representativo de los aros usados por los miembros de la toldería, los aros upül y los chahuay discoidales parecen haber sido mucho más comunes que los aros de forma anular, o por lo menos más fáciles de obtener. El análisis de estos tipos evidencia una gran variedad de niveles orfebres. De manera general la fundición es buena o regular y el martillado de buena calidad. Observamos un alto nivel en la confección de los aros upül; un nivel alto-medio en el de los aros anulares, puesto que su fabricación requiere una mano experta en la técnica de la fundición; y un nivel medio-bajo en el de los chahuay discoidales, con un trabajo que necesita un cierto conocimiento metalúrgico pero que integra una decoración de bajo nivel. En el caso del aro upül, la alta calidad estándar de la factura y de la materia prima de las piezas estaría evidenciando una fabricación más selectiva e incluso controlada de los aros ceremoniales.

Las diferentes fuentes etnohistóricas sugieren un cuidado en la selección de los metales empleados en la realización de las joyas, cuyo peso determinaba el importe que se le pagaría al platero por su trabajo orfebre (Morris von Bennevitz 1997:20, Claude Joseph 1930:525). En el grupo de aros estudiado se observó una gran diversidad en las aleaciones metálicas, con tenores variados en plata, con excepción de los aros upül que presentan siempre una proporción de metal preciado relativamente alta. De hecho, esta variabilidad en las aleaciones de los aros discoidales y anulares parece indicar, para estos tipos de aros de uso cotidiano, un empleo indiferenciado de la materia prima a disposición.

La presencia de aleaciones cobre-zinc-níquel en los aros discoidales y anulares denota también la factura relativamente reciente de un número considerable de piezas. En el caso de la colección La Vaulx que fue constituida en 1896, es notable la importancia del uso de monedas en cuproníquel. Aunque la acuñación de estas monedas se había iniciado en Argentina ese mismo año, es altamente probable que las monedas empleadas en la fabricación de los aros tengan un origen chileno. La presencia de cuproníquel estaría entonces planteando una fecha de fabricación posterior a 1871 para las piezas en cuestión, indicando que algunos de los aros obtenidos por La Vaulx fueron producidos en el cuarto de siglo anterior a su exploración patagónica. Por el contrario, la ausencia de cuproníquel no es necesariamente un indicador cronológico, en la medida que el platero o el comanditario de un par de aros pudo haber seleccionado para su fabricación monedas antiguas o joyas en desuso o descompuestas, por algún motivo específico o simplemente porque era la materia prima que tenía a disposición.

El análisis de algunos aros obtenidos por martillado corrobora las observaciones tecnológicas desarrolladas en las publicaciones existentes (Claude Joseph 1928, 1930; Mora 1986); en ciertos casos, se pudo verificar una producción por martillado de una moneda, tal como lo documentó Claude Joseph para la producción de los chahuay discoidales (1930). Sin embargo, en la muestra analizada, es notoria la prevalencia de la fundición para la fabricación de las joyas: sistemático en los aros anulares, frecuente en los aros rectangulares y discoidales. Esto sugiere que los creadores de las joyas debieron dominar esta técnica, que requiere conocimiento metalúrgico y 
tiempo de factura. El trabajo a partir de monedas requiere solamente una práctica de martillado. Por otro lado, en los chahuay discoidales realizados por fundición se pudo observar una manufactura en dos tiempos y por manos distintas: una mano experta que fundió el cuerpo de la pieza y una mano mucho más insegura que la decoró. De hecho, estas piezas y el resto de los aros de la colección La Vaulx reflejan una amplia variedad de artesanos, con instrumentos y capacidades diversas 5 , que cuestionan la identidad y el papel del platero.

Varias fuentes informan acerca del trabajo del platero indígena y de su presencia junto a los grandes caciques de artesanos que se dedicaban a la confección de su apero y las joyas de sus mujeres (Coña 2006; Mansilla 1984; Zeballos 1960). Sin embargo probablemente no toda toldería tuviera un platero de oficio fijo, o su presencia podría haber desaparecido en tiempos de mayor pauperización. También se sabe que las mujeres jugaron un papel importante en la fabricación personal de las joyas, ya sea en la sociedad mapuche (Claude Joseph 1930:520) o en la tehuelche (Musters 1964:248; Priegue 1996:62 y 69; Priegue 2006:26), lo que podría explicar una decoración más sencilla de las joyas. También se sabe que ciertos elementos de joyas se adquirían por separado y se atesoraban hasta ser empleados, tal como lo pone en evidencia la colección La Vaulx, que incluye una serie de apéndices decorativos de pectorales que fueron obtenidos sueltos, o el testimonio de Luisa Pascual, "hija de un tehuelche meridional y un araucano chileno", que confirma que "se solía tener bolsitas llenas de piezas hechas de plata"6. Este punto podría explicar ciertas aleaciones, como aquellas integrando metal antiguo (aleaciones de plata) y metal moderno (cuproníquel).

La Vaulx adquirió durante su exploración en la Patagonia lo que definió en el registro del museo como el "instrumental completo del joyero indígena": este incluye un fuelle, una tenaza, una pinza y una cajita de madera para contener los desechos metálicos ${ }^{7}$. Lamentablemente no especifica en sus escritos en qué circunstancias y dónde obtuvo las piezas, pero parece extraño que un platero aceptase deshacerse de su material de trabajo, salvo si este ya no le era de utilidad. Si nos fiamos de lo que nos indica el registro de la colección, el material obtenido estaría reflejando el taller de un artesano fundidor más que de un orfebre. La ausencia de martillo y de cinceles o punzones sugiere un trabajo del metal relativamente limitado, por fundición básicamente, como lo muestra el análisis tecnológico de varios de los aros. La confrontación de este instrumental limitado con la lista completa de herramientas que le encarga el platero Ramón a Jorge Claras (citada en Palavecino 1966) sugiere dos modos de trabajar el metal radicalmente distintos. Pero lo que se le cedió a La Vaulx quizás fue solo lo que se le quiso dar: un orfebre no se separaría de sus herramientas de decoración (fabricadas especialmente para él). Dicho esto, las observaciones tecnológicas de los chahuay discoidales obtenidos en la toldería de Saygüeque evidencian que los cuerpos de las piezas fueron realizados por expertos en la técnica de fundición, para luego ser adquiridos, decorados y completados por terceros con el fin de adaptarlas al gusto y a las necesidades de sus propietarias.

Esta gran diversidad de manos estaría señalando el acceso, por elección o necesidad (ausencia de un orfebre a disposición), al trabajo del metal por una variedad de personas, pertenecientes o externas a la toldería, ya sea geográfica o cronológicamente, puesto que las joyas también podrían haber sido heredadas de generación en generación (Mora Penroz 1986:41). También podría deberse a la pauperización progresiva de la toldería, o a su desplazamiento hacia el Sur en donde ya no se beneficiaría de los intensos intercambios transcordilleranos que controlaba otrora. El par de upül $\mathrm{n}^{\circ} 130$ (Figura 4), de calidad tan excepcional y única en el conjunto considerado, podría estar reflejando una manufactura más antigua, de un período de mayor bienestar en la toldería, cuando todavía se podía contratar un platero de oficio. La Vaulx cuenta que en el momento de su llegada a los toldos de Saygüeque las mujeres llevaban sus mejores alhajas, entre ellas los famosos aros upül. Pocas son, sin embargo, las joyas que se observan en las fotos que realizó durante su estadía en los toldos, a excepción del retrato de las hijas del cacique ${ }^{8}$, en el que dos de ellas llevan aros chahuay discoidales, mientras que la tercera luce aros de manufactura hispana. A esta colección, que estaría reflejando una producción arraigada geográficamente, vinculada por lo menos en parte con la territorialidad original de Valentín Saygüeque en la Patagonia septentrional, solo llegaron algunos de los restos de las riquezas atesoradas en los toldos en los tiempos de la Gobernación indígena de las Manzanas.

Agradecimientos: Quisiéramos agradecer la invitación de Valentina Figueroa, Luis González y 
Diego Salazar a participar del Simposio 785 (Minería y Metalurgia en los Andes) que organizaban en el marco del $54^{\circ}$ Congreso de Americanistas: este artículo se basa en gran parte en la investigación presentada en Viena, junto a Richard Haas, Leonor Adán y Julio Vezub. Nuestro análisis parte del estudio contextual de la colección La Vaulx, que llevamos a cabo con Julio Vezub, y aquel del fondo Georg Schythe, conducido junto a Richard Haas. Le damos también las gracias a Diego Milos, por compartir los preciados datos que ha ido recabando del tratamiento de los archivos de Claude Gay. El estudio analítico de las joyas se hizo en los laboratorios del Centre de Recherche et de Restauration des Musées de France. Quisiéramos agradecer al equipo del acelerador de partículas AGLAE por su apoyo técnico, así como a Dominique Bagault por la fotografía de los objetos, y a Thierry Borel por sus radiografías. Agradecemos también los valiosos comentarios y sugerencias de los dos evaluadores anónimos de este artículo.

\section{Referencias Citadas}

Aldunate del Solar, C. 1983. Reflexiones acerca de la platería mapuche. En Platería Araucana, editado por C. Aldunate del Solar y W. Reccius, pp. 10-14. Museo Chileno de Arte Precolombino, Santiago.

Aldunate del Solar, C. 2008. Sobre la platería mapuche del otro lado de la cordillera. En Platería de las Pampas, editado por C. Caraballo de Quentín, pp. 17-19. Larivière, Buenos Aires.

Aldunate del Solar, C. y W. Reccius 1983. Platería Araucana. Museo Chileno de Arte Precolombino, Santiago.

Auer, E. 2001. Das Nickel im Münzwesen von der Antik bis zum EURO. En 250 Jahre Nickel: vom Nickel zum Euro, editado por E. Auer, S. Müller y R. Slotta, pp. 111-202. Verlag Deutsches Bergbau-Museum, Bochum.

Berón, M. 2010. Circuitos regionales y conflictos intergrupales prehispánicos. Evidencias arqueológicas de violencia y guerra en la Pampa Occidental Argentina. Actas del XVII Congreso Nacional de Arqueología Chilena, 9-14 Octubre 2006, Valdivia, Chile, tomo 1, pp. 493-503.

Berón, M. y L.R. González 2006. Análisis de composición de adornos metálicos de un contexto funerario de cazadoresrecolectores. El sitio Chenque I, provincia de La Pampa. En Metodologías Científicas Aplicadas al estudio de los Bienes Culturales, editado por A. Pifferetti y R. Bolmaro, pp. 82-86. Ed. Humanidades y Artes Ediciones, Rosario.

Campbell T., R. 2004. El trabajo de metales en la Araucanía (siglos X-XVII d. C.). Universidad de Chile, Santiago.

Caraballo de Quentín, C. (coord.) 2008. Platería de las Pampas. Buenos Aires, Larivière.

Claude Joseph, H. 1928. La Platería araucana. Anales de la Universidad de Chile, 2da serie, 1er trimestre de 1928, Año VI. Establecimientos Gráficos Ballcells \& Co, Santiago.

Claude Joseph, H. 1930. Los adornos araucanos de Lanahue. Revista Universitaria 15/5-6:512-518.

Coña, P. 2006. Testimonio de un Cacique Mapuche. Pehuén, Santiago (1 $1^{\text {ra }}$ ed.1930).

Dillehay, T.D. 2009. Moon Tears. Mapuche art and cosmology. En Moon Tears. Mapuche Art and Cosmology from the Domeyko Cassel Collection, Santiago, Chile, pp. 8-18. Americas Society, New York.
Guerra, M.F. 2000. The mines of Potosi: a Silver Eldorado for the European economy. En Ion Beam Study of Art and Archaeological Objects, editado por G. Demortier y A. Adriaens, pp. 88-94. Directorate-General for Research, European Communities.

Guerra, M.F. 2004. The circulation of South-American precious metals in Brazil in the end of the $17^{\text {th }}$ Century. Journal of Archaeological Sciences 31:1225-1236.

Guerra, M. F. 2008. An Overview on the Ancient Goldsmith's Skill and the Circulation of Gold in the Past: the Role of X-ray Based Techniques ». X-ray Spectrometry 37-4:317-327.

Guerra, M.F. 2011. Objetos de oro y plata sudamericanos: análisis científicos para estudio y autenticación. Actas del II Congreso de Arqueometría de Lima (2009), editado por L. Vetter, R. Vega-Centeno, P. Olivera y S. Petrick, pp. 13-28. Universidad Nacional de Ingeniería-IPEN, Lima.

Guerra, M.F. y P. Núñez-Regueiro 2012. Indigenous silver jewellery of Northern Patagonia (19 ${ }^{\text {th }}$ century): Analytical approach to composite objects. X-Ray Spectrometry 41:342-349.

Guerra, M.F. e I. Tissot 2013. The role of nuclear microprobes in the study and conservation of gold and silver cultural heritage items: An overview. Nuclear Instruments and Methods B 306:227-231.

Hartmann, G. 1974. Silberschmuck des Araukaner, Chile. Veröffentlichungen des Museums für Völkerkunde Berlin, 30. Museums für Völkerkunde Berlin, Berlin.

Hayduk, A. 1981-1982. Cementerio "Rebolledo Arriba", departamento Aluminé, provincia de Neuquén. Relaciones de la Sociedad Argentina de Antropología 14-2:125-145.

Inostroza, J.E. y H. Mora O. (coord.). 1986. Tesoros de la Araucanía. Colección Raúl Morris von Bennewitz. Ilustre Municipalidad de Los Ángeles, Museo Regional de Araucanía, Temuco.

Inostroza, J.E., R. Morris von Bennevitz y H. Mora O. 1986. Descripción de la muestra. En Tesoros de la Araucanía. Colección Raúl Morris von Bennewitz, editado por J.E. Inostroza y H. Mora O., pp. 14-33. Ilustre Municipalidad de Los Ángeles, Museo Regional de Araucanía, Temuco.

Inostroza, J.E. y M. Sánchez A. 1986. La Platería en los sitios arqueológicos. En Tesoros de la Araucanía. Colección Raúl 
Morris von Bennewitz, editado por J. E. Inostroza y H. Mora O., pp. 68-79. Ilustre Municipalidad de Los Ángeles, Museo Regional de Araucanía, Temuco.

La Vaulx, H. (de). 1901. Voyage en Patagonie. Hachette, Paris. Lista, R. 2006. Los Indios Tehuelches. Una Raza que Desaparece. Patagonia Sur Libros, Buenos Aires (1 ${ }^{\text {ra }}$ ed esp. 1894).

Mansilla, L. V. 1984. Una excursión a los indios ranqueles. Elefante Blanco, Buenos Aires (1 ${ }^{\text {ra }}$ ed 1870).

Martinic, B. M. 1995. Los Aónikenk, historia y cultura. Ediciones Universidad de Magallanes, Punta Arenas.

Martinic, B.M. y A. Prieto I. 1988. Artesanía aonikenk sobre metal a la luz de hallazgos arqueológicos. Anales del Instituto de Patagonia 18-1:99-105.

Mera, C.R., B. Mille, D. Munita y V. Figueroa 2015. Copper earrings in La Araucanía: Earliest evidence of metal usage in Southern Chile. Latin American Antiquity 26:106-119.

Millán de Palavecino, M. D. 1966. Platería araucana de la Pampa bonaerense. Etnia 4:11-19.

Mora O., H. 1986. El Arte de trabajar los metales. En Tesoros de la Araucanía. Colección Raúl Morris von Bennewitz, editado por J. E. Inostroza y H. Mora O., pp. 52-66. Ilustre Municipalidad de Los Ángeles, Museo Regional de Araucanía, Temuco.

Mora Penroz, Z. 1986. La plata y su vinculación al universo femenino de la magia. En Tesoros de la Araucanía. Colección Raúl Morris von Bennewitz, editado por J. E. Inostroza y H. Mora O., pp. 34-48. Ilustre Municipalidad de Los Ángeles, Museo Regional de Araucanía, Temuco.

Morris von Bennewitz, R. 1997. Los Plateros de la Frontera y la Platería Araucana. Universidad de la Frontera, Temuco.

Munita, D., R. Mera, V. Figueroa y B. Mille 2010. Evidencias tempranas del trabajo de metales en la Araucanía. Adornos de cobre del complejo Pitrén. Actas del II Congreso de Arqueometría de Lima (2009), editado por L. Vetter, R. Vega-Centeno, P. Olivera y S. Petrick. Universidad Nacional de Ingeniería-IPEN, Lima.
Musters, G. 1964 [1871]. Vida entre Los Patagones. Un Año de excursiones por Tierras No Frecuentadas desde el Estrecho de Magallanes hasta el Río Negro. Solar/Hachette, Buenos Aires.

Núñez-Regueiro, P. 2014. The ethnographic œuvre of Fr 'R. H. Claude Joseph' and the Mapuche collections of the Musée du Quai Branly. The forgotten history of French entomologist Hippolyte Janvier's sojourn in the Araucanía region of Chile (1926-1932). Journal of the History of Collections 27(1):57-72.

Núñez-Regueiro, P. y J. Vezub 2012. Sur les traces du Géant Patagon. L'histoire de la collection Henry de La Vaulx du Musée du quai Branly (1896-1897). Journal de la Société des Américanistes 98(1):133-169.

Pereda, T. 2002. La platería en las tierras de Este y del Oeste. En Hijos del Viento. Arte de los Pueblos del Sur Siglo XIX, editado por I. Iriarte y T. Pereda, pp. 65-74. Fundación PROA, Buenos Aires.

Priegue, C.N. 1996. Similitudes entre artesanías mapuches y aonikenk: la platería. En Araucanía y Pampas. Un Mundo Fronterizo en América del Sur, editado por J. Pinto Rodríguez, pp. 62-71. Universidad de la Frontera, Temuco.

Priegue, C.N. 2007. En Memoria de los Abuelos. Historia de Vida de Luisa Pascual, Tehuelche. Publitek, Bahía Blanca.

Quiroz, D. y M. Sánchez (coord.) 1997. La Isla de las Palabras Rotas. Biblioteca Nacional de Chile, Centro de Investigaciones Diego Barros Arana, Santiago.

Reccius, W. 1983. Evolución y caracterización de la platería araucana. En Platería Araucana, editado por C. Aldunate del Solar y W. Reccius, pp. 17-31. Museo Chileno de Arte Precolombino, Santiago.

Sánchez A., M. 1985. Sepultura de un platero y piezas de platería del cementerio Pitraco I, comuna de Nueva Imperial. IX Región. Boletín del Museo Regional de la Araucanía 2:141-145.

Vezub, J. 2009. Valentín Saygüeque y la Gobernación Indígena de las Manzanas. Poder y Etnicidad en la Patagonia Septentrional (1860-1881). Colección Prometeo Bicentenario, Buenos Aires.

\section{Notas}

1 La escritura de los términos en mapudungun sigue el grafemario del Alfabeto Mapuche Unificado.

2 La colección platera de la misión La Vaulx está inventariada de $\mathrm{N}^{\mathrm{o}} 71.1898 .59 .1$ a 71.1898.59.130. En el artículo las piezas aparecen nombradas por su número en la colección, por ejemplo $\mathrm{N}^{\circ} 130$ para 71.1898.59.130.

3 Reccius (1986:19) denomina esta forma "chaway-chapel" y Morris von Bennewitz (1997 :72-74) "upul”. Según Augusta, las voces chapëll y upül son sinónimos que designan "zarcillos de plata, cuadrangulares" (Augusta 1916:18 y 242).

4 Archivos Ethnologisches Museum de Berlin, legajo $\mathrm{N}^{\circ} 308$.

5 Claude Joseph evoca, en lo que se refiere a la región de Lanahue (Araucanía chilena), que "algunos [plateros] desempeñan su oficio con ciertas comodidades y poseen verdaderos talleres con fraguas, crisoles, yunques, prensas, tijeras y limas. Además de estos profesionales otros araucanos de ambos sexos se dedican a fabricar tal o cual clase de adornos como especialistas" (Claude Joseph 1930:520). Para una contextualización del trabajo pionero del etnólogo Claude Joseph, referirse a Núñez-Regueiro 2014.

6 Parte de ellas parecen haber sido elementos descompuestos de joyas, ya que en el caso citado se desparramaban sobre la sepultura de un difunto junto con "patacones y chaquiras de colores" sueltas (Priegue 2007: 55).

7 Musée du quai Branly, No 71.1899.8.92, 71.1899.8.54, 71.1899.8.94 y 71.1899.8.93.

8 "Las hijas del cacique Saygüeque", Henry de La Vaulx, 1896, Société de Géographie de Paris, ${ }^{\circ}$ inv. Wf 210-44. 
